\title{
Rancang Bangun Sistem Informasi Persediaan Bahan Baku Pada PT. Gema Putra Abadi Bekasi
}

\author{
Hesti Rian $^{\left.1)^{*}\right)}$, Kanif Yudhistira ${ }^{2)}$ \\ 1)2) Program Studi Manajemen Informatika, Politeknik LP3I Jakarta \\ ${ }^{*}$ Correspondence Author: hestiriangustiawan@gmail.com, Jakarta, Indonesia \\ DOI: https://doi.org/10.37012/jtik.v6i2.307
}

\begin{abstract}
Abstrak
Dalam sebuah pabrik sistem dan tata kelola persediaan barang sangatlah penting oleh sebab itu sebuah perusahaan harus selalu mengikuti perkembangan terlebih dibidang industri dan teknologi dalam era ini sudah memasuki era industry 4.0, dimana semua data akan terkomputerisasi / paperless selain akan menghemat tempat untuk penyimpanan data sistem komputerisasi sangatlah efisien dan dapat membantu pengelolaan data. Pada PT. Gema Putra Abadi sistem pengelolaan data masih menggunakan kertas / hardcopy yang tentu saja memiliki banyak resiko seperti kerusakan data dan kehilangan data maka dari itu penulis membuat "Rancang Bangun Sistem Informasi Persediaan Bahan Baku Pada PT.Gema Putra Abadi di Bekasi” yang bertujuan untuk mempermudah dan membantu sistem tata kelola pada PT. Gema Putra Abadi. Penulis berharap sistem informasi tersebut bisa meningkatkan kinerja karyawan dan mempermudah dalam tata kelola data.
\end{abstract}

Kata Kunci : sistem, komputerisasi, persediaan.

\begin{abstract}
In the factory, the system and management of inventory are very important, therefore a company must always follow developments, especially in industry and technology, in this era it has entered the industrial era 4.0, where all data will be computerized / paperless in addition to saving space for storing computerized system data. very efficient and can help data management. At PT. Gema Putra Abadi data management system still uses paper / hardcopy which of course has many risks such as data damage and data loss, therefore the authors make "Design and Construction of Raw Material Inventory Information Systems at PT. Gema Putra Abadi in Bekasi" which aims to simplify and assisting the governance system at PT. Echo of the Eternal Son. The author hopes that the information system can improve employee performance and facilitate data management.
\end{abstract}

Keywords : systems, computerized, inventory.

\section{PENDAHULUAN}

Persediaan barang merupakan hal yang sangat penting bagi suatu perusahaan dan wirausahawan. Persediaan diperlukan untuk menciptakan penjualan, penjualan akan menghasilkan keuntungan. Dari keuntungan tersebut suatu perusahaan akan bisa terus berkembang. Pada saat ini perkembangan teknologi informasi semakin berkembang pesat. Kebutuhan akan kecepatan dan keakuratan dalam penginputan, pengolahan dan penyimpanan data sangat diperlukan. Maka dari itu suatu perusahaan maupun organisasi sudah banyak yang menggunakan sistem informasi yang berbasis teknologi. Pada saat sekarang ini PT. Gema Putra Abadi masih belum sepenuhnya menggunakan sistem informasi yang terkomputerisasi. Dilihat dari jumlah pembelian barang yang semakin banyak dan permintaan customer yang semakin menigkat. Maka pencatatan dan 
penyimpanan data pastinya memakan waktu yang lama. Penyimpanan data masih menggunakan cara manual, maka dari itu harus menerapkan sistem informasi yang terkomputerisasi. Karena belum sepenuhnya menerapkan sistem komputerisasi maka sering terjadi permasalahan dalam pengelolaan data seperti ketidakakuratan dalam penginputan data. Selain itu akan menghambat dalam pembuatan laporan dikarenakan pencarian data yang berbentuk dokumen cetak sangat banyak. PT. Gema Putra Abadi bergerak dalam bidang usaha manufaktur yang memproduksi Karton Corrugated dan Foam.

PT. Gema Putra Abadi harus menerapkan sistem komputerisasi untuk membantu pengolahan data persediaan barang yang diharapkan dapat meningkatkan proses kerja, meningkatkan kapasitas dalam penyimpanan data, memudahkan dan mempercepat dalam pencarian informasi yang dibutuhkan dan mengurangi biaya operasional. Dengan adanya masalah yang telah disebutkan di atas, Pimpinan perlu merubah metode penginputan, pengelolaan dan penyimpanan data yang pada saat ini masih menggunakan dokumen cetak menjadi metode yang terkomputerisasi dan otomatis. Perancangan sistem informasi persediaan barang yang berbasis web ini diterapkan agar dapat mengelola data persediaan barang secara efektif sesuai alur yang telah ditentukan oleh Pimpinan. Pengarsipan dokumen persediaan barang dilakukan secara elektronik, yaitu penyimpanan dokumen berbentuk softcopy, dan dilengkapi dengan laporan dokumen pembelian.

\section{METODE}

Metode-metode yang digunakan untuk mendapatkan data dalam pembuatan penelitian ini sebagai berikut:

1. Observasi

Penulis melakukan observasi terhadap Kegiatan persediaan bahan baku pada PT. Gema Putra Abadi di Bekasi.

2. Wawancara

Penulis melakukan wawancara dengan Kepala PPIC dan mengajukan pertanyaanpertanyaan terkait persediaan bahan baku.

3. Studi Pustaka

Pengumpulan data dari buku - buku yang sesuai dengan tema permasalahan, mislanya buku analisis dan desain informasi.

\section{HASIL DAN PEMBAHASAN}


Rancangan usulan seperti digambarkan pada Use Case diagram di bawah ini :

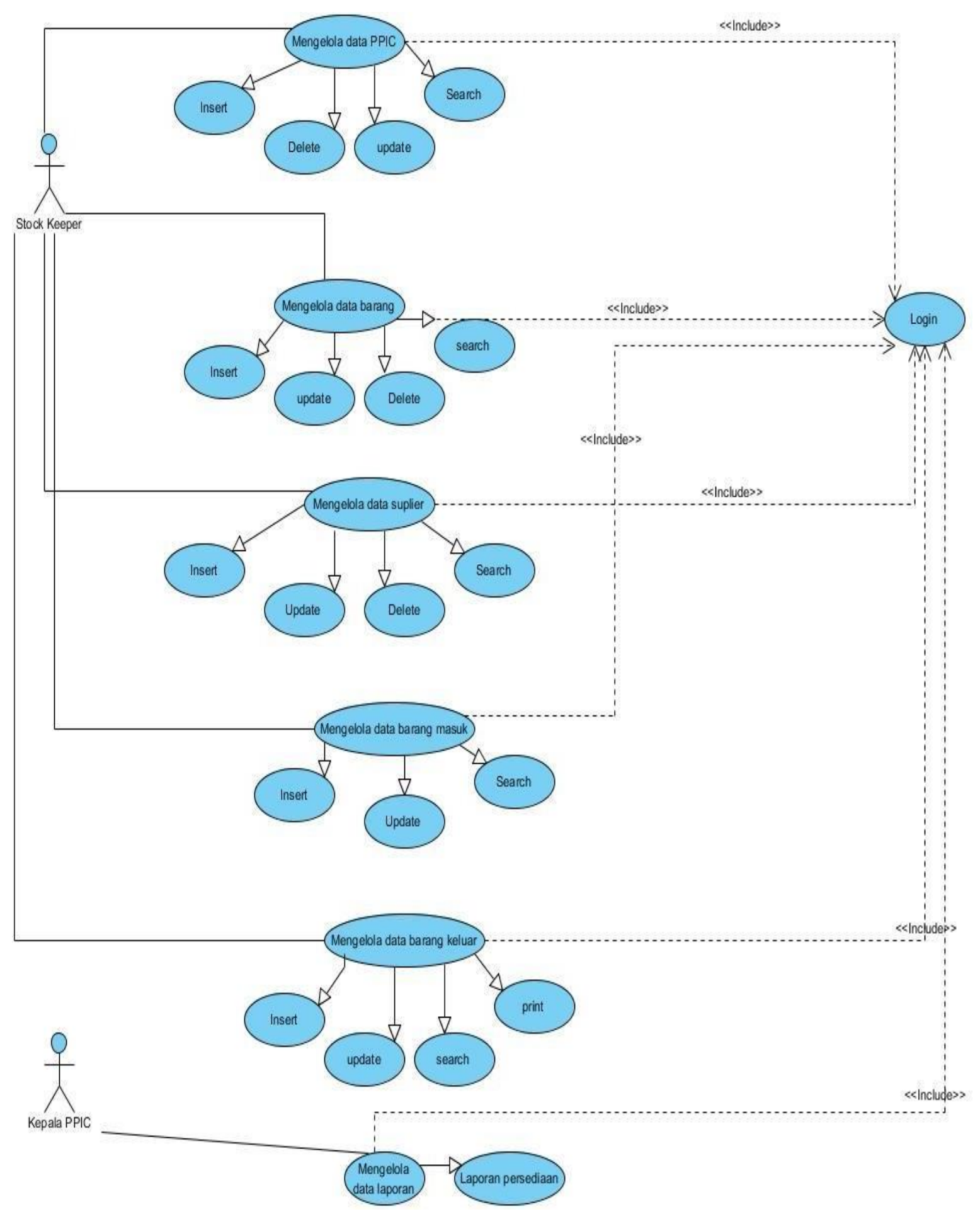

Gambar 1. Use Case Diagram 


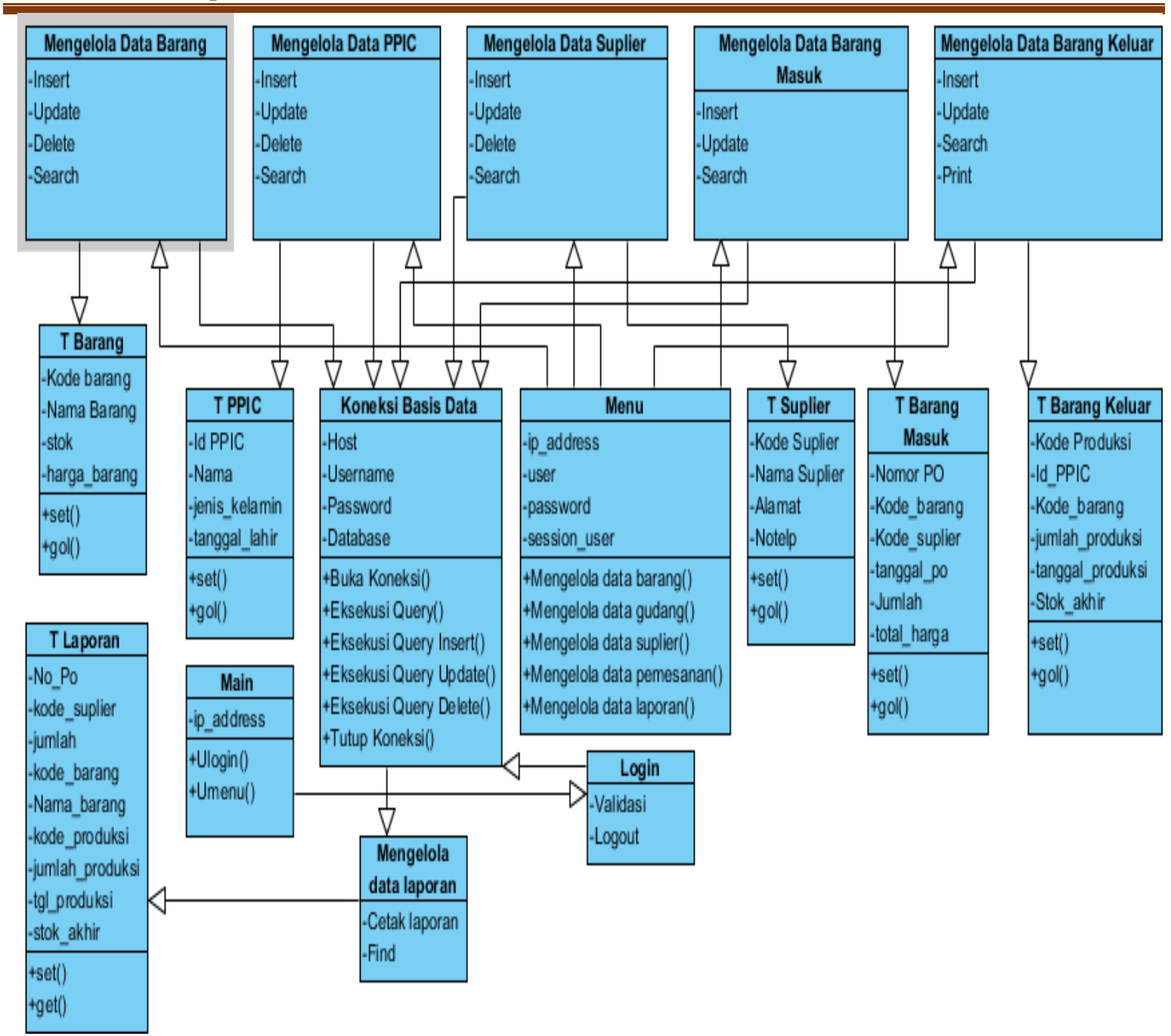

Gambar 2. Class Diagram 


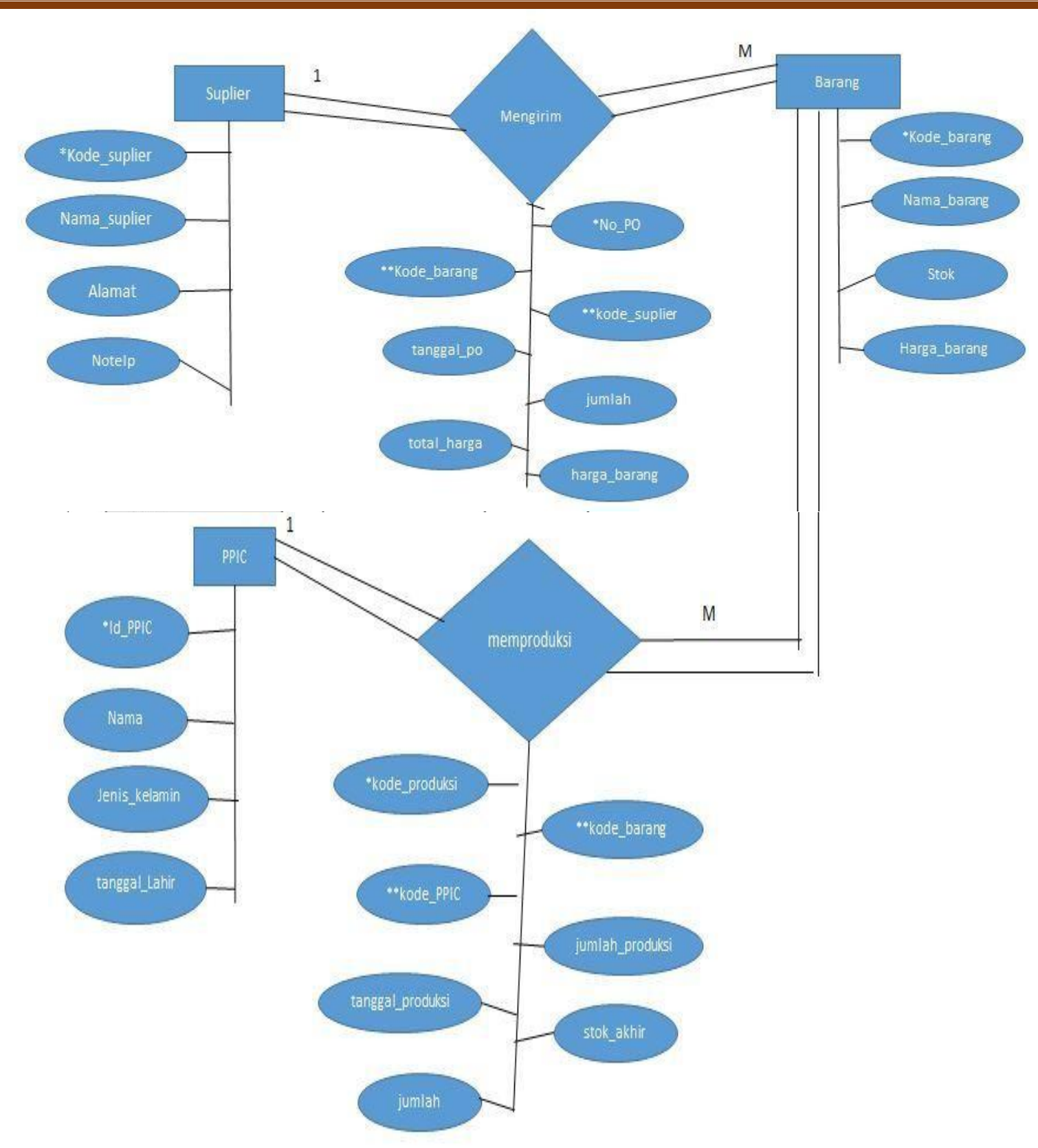

Gambar 3. Entity Relationship Diagram

\begin{tabular}{|c|c|c|c|c|c|c|}
\hline \multirow{4}{*}{$\begin{array}{l}\text { No_PO } \\
\text { Kode_suplier } \\
\text { tanggal_PO }\end{array}$} & \multicolumn{6}{|c|}{ Form barang masuk } \\
\hline & & No_PO & Kode_barang & Jumlah & harga_barang & Total_barang \\
\hline & & & & & & \\
\hline & & & & & & \\
\hline Add & Search & No_PO & Kode_barang & Jumlah & harga_barang & Total_barang \\
\hline Save & Update & & & & & \\
\hline & & No_PO & Kode_barang & Jumlah & harga_barang & Total_barang \\
\hline
\end{tabular}

Gambar 4. User Interface Form Barang Masuk 


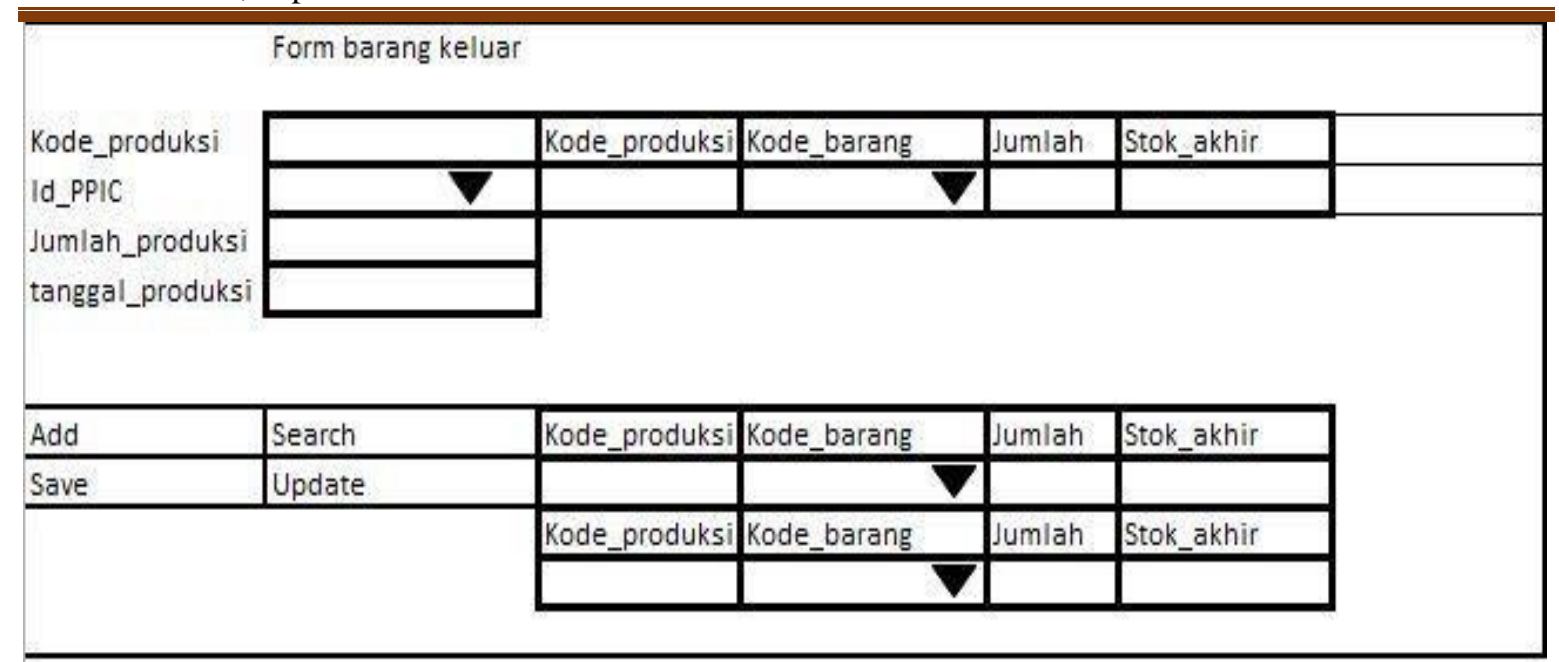

Gambar 5. User Interface Form Barang Keluar

\section{Kebutuhan Infrastruktur :}

1. Sistem Operasi

Windows 10

\section{Kebutuhan Hardware}
a. Processor AMD A4
b. Random Access Memory (RAM) DDR3 4GB
c. Hard Disk 500GB
d. Monitor

\section{Jaringan Komputer}

Xampp

\section{Kebutuhan Software}
a. Tools Editor
: Atom, Notepad ++
b. Web Browser
: Google Chrome
c. Web server
: Xampp
d. Database
: Mysql
e. Program
: PHP

\section{KESIMPULAN DAN REKOMENDASI}

Penyimpanan data barang, stok, laporan persediaan masih menggunakan hardcopy, jadi penyimpanan seluruh data memerlukan wadah dan ruangan yang besar. Hal ini sangat menyulitkan stock keeper jika sewaktu-waktu membutuhkan data. Dalam pencarian data tersebut membutuhkan waktu yang lama, tapi dengan adanya perancangan sistem informasi maka pencarian data yang dibutuhkan akan lebih cepat dan mudah didapatkan. Dengan adanya program aplikasi sistem informasi persediaan bahan baku ini, dapat 
mengurangi kesalahan dan mempermudah dalam mengelola data baik dalam pencarian arsip, penginputan data pembuatan laporan transaksi sesuai dengan kebutuhan serta proses pengarsipan pun dapat tersimpan dengan baik. Adanya perancangan sistem ini akan memudahkan tugas seorang stock keeper dalam melakukan proses penghitungan persediaan bahan baku pada PT. Gema Putra Abadi di Bekasi.

\section{REFERENSI}

Handoko, Hani T. 2017. Dasar-dasar Manajemen Produksi dan Operasi. BPFE : Yogyakarta.

Helmawati. 2015. Sistem Informasi Manajemen Pendidikan Agama Islam. PT. Remaja Rosdakarya : Bandung.

Kadir, Abdul. 2013. Pemrogramman Database MySQL untuk Pemula. MediaKom : Yogyakarta.

Pratama, I Putu Agus Eka. 2016. Integrasi dan Imigrasi Sistem. Informatika : Bandung.

Pratama, I Putu Agus Eka. 2014. Sistem Informasi dan Implementasinya. Mitra Wacana Media : Jakarta.

Rosa, A.S, M.Salahuddin. 2014. Rekayasa Perangkat lunak Terstruktur danBeriorientasi Objek. Informatika : Bandung.

Rosa, A.S, M.Salahuddin. 2017. Logika Algoritma dan Pemrograman Dasar. Moduka : Bandung.

Raharjo, Budi. 2015. Mudah belajar php.Informatika : Bandung.

Suprapto, Falahah. 2018. Rekayasa Perangkat Lunak. Lentera Ilmu Cendikia : Jakarta. 